\title{
A New Thalassosmittia Strenzke and Remmert, 1957 Out of the Sea: T. amazonica N. SP. From the Amazon Rainforest, Brazil (Diptera: Chironomidae, Orthocladinae)
}

\author{
Trond Andersen ${ }^{1}$ and Luiz Carlos Pinho ${ }^{2}$ \\ ${ }^{1}$ Department of Natural History, University Museum of Bergen, University of Bergen, \\ P.O. Box 7800, NO-5020 Bergen, Norway.E-mail: trond.andersen@um.uib.no \\ ${ }^{2}$ Universidade Federal de Santa Catarina, Centro de Ciências Biológicas, Departamento de Ecologia e \\ Zoologia, 88040-901, Florianópolis - SC, Brazil.E-mail: luiz.pinho@ufsc.br
}

\begin{abstract}
The orthoclad Thalassosmittia amazonica $\mathrm{n}$. sp. is described based on a male collected in a light trap in the Amazon rainforest. The species is easily separated from its congeners as it has a strongly reduced palp with only a single palpomere.
\end{abstract}

\section{Introduction}

Most of the 10 known species of Thalassosmittia Strenzke et Remmert are marine shore dwellers (Tokunaga 1936; Strenzke and Remmert 1957; Morley and Ring 1972; Sæther and Andersen 2011; Andersen et al. 2013). However, Wang and Sæther (1993) described T. montana Wang et Sæther from Xizang (Tibet) in China, where it was taken at $2500 \mathrm{~m}$ altitude. The species shows significant differences from the other species of the genus in the wing venation, virga and the phallapodeme. At the same time features of the anal point, gonostylus and the chaetotaxy is characteristic of Thalassomittia and the species keys without difficulty to Thalassosmittia in Cranston et al. (1989). Wang and Sæther (1993) therefore placed the new species in Thalassosmittia and concluded that even if it eventually might be placed in a separate genus it is evidently closely related to Thalassosmittia.

Sorting through material collected in Manaus in the Amazon, we came across a species which keys to Thalassosmittia in Cranston et al. (1989). It has the features of the anal point and gonostylus characteristic of the genus and it groups with T. montana in the wing features, like cuneiform shape, $R_{2+3}$ running in the middle between $R_{1}$ and $\mathrm{R}_{4+5}$ and absence of setae on R. However, it differs in several other features such as having bare eyes and a reduced palp, a phallapodeme with triangular aedeagal lobe with strongly sclerotized median margin, and a strong virga with lateral lamellae. Even so we place it tentatively in Thalassosmittia. As with T. montana it might deserve a separate genus, but for the time being we are probably better served with keeping both in the genus Thalassosmittia awaiting the discovery of more species.

\section{Material and Methods}

The specimen examined was collected in a light trap in the Reserva Adolpho Ducke in Manaus and preserved in alcohol. It was later mounted in Canada Balsam following the procedure outlined by Sæther (1969). The general morphology follows Sæther (1980).

The holotype is deposited in Museu de Zoologia da Universidade de São Paulo, São Paulo, Brazil (MZSP).

\section{Thalassosmittia Strenzke and Remmert}

Thalassosmittia Strenzke and Remmert, 1957: 270.

Syn.: Saunderia Sublette, 1967: 318. Sæther (1977).

Syn.: Ikiprimus Sasa and Suzuki, 1999b: 157. Yamamoto (2004).

Type species: Camptocladius thalassophilus Bequaert and Goetghebuer, 1914: 373.

Other included species: Thalassosmittia atlantica (Storå, 1936: 27); T. christinae Sæther and Andersen, 2011: 10; T. clavicornis (Saunders, 1928: 528); T. ikiijea (Sasa and Suzuki, 1999b: 157); T. marina (Saunders, 1928: 526); T. montana Wang and Sæther, 1993: 212; T. nemalione (Tokunaga, 1936: 305); T. pacifica (Saunders, 1928: 523); T. tusimoefea (Sasa and Suzuki, 1999a: 82).

The emended diagnosis is based on the diagnosis in Cranston et al. (1989: 243), including the emendations given by Wang and Sæther (1993: 211).

\section{Emended diagnosis, males}

Small species, wing length up to $2.0 \mathrm{~mm}$.

Antenna. With 7-8 or 11-13 flagellomeres; antennal groove, when present, beginning at flagellomere 3 or 4; sensilla chaetica variable, present on all flagellomeres in reduced species, perhaps sometimes absent. Antennal plume well developed, variable reduced or virtually absent. Ultimate flagellomere tapering to rounded apex, with- 
out subapical, strong setae.

Head. Eye round, without dorsomedial extension; bare, pubescent or hairy. Up to 10 uniserial temporals present, including 1-2 inner verticals. Palp with single segment with about 8 sensilla clavata or with 5 segments, often short, with 1-3 sensilla clavata.

Thorax. Antepronotum weakly developed, lobes widely separated by weakly projecting scutum. Few weak, decumbent acrostichals present on anterior to median scutum. Dorsocentrals, prealars and scutellars few, uniserial.

Wing. Membrane without setae, finely punctate. Anal lobe absent to well developed. Costa strongly extended. $\mathrm{R}_{2+3}$ either running close to or virtually fused with $\mathrm{R}_{4+5}$, or running in the middle between $\mathrm{R}_{1}$ and $\mathrm{R}_{4+5} ; \mathrm{R}_{4+5}$ ending distal to, at same level, or proximal to end of $\mathrm{M}_{3+4} ; \mathrm{Cu}_{1}$ weakly to moderately sinuous; $\mathrm{FCu}$ far distal to $\mathrm{RM}$; postcubitus and anal vein extend to, or slightly beyond, $\mathrm{FCu}$. $\mathrm{R}, \mathrm{R}_{1}$ and $\mathrm{R}_{4+5}$ with or without seta. Squama bare.

Legs. All legs with 1 strong outer tibial spur; inner spur, if present, very small; comb normal. Sensilla chaetica absent. Pulvilli absent or vestigial; empodium elongate.

Abdomen. With few scattered setae.

Hypopygium. Anal point broad, apically rounded, covered with short to moderately long microtrichia and setae. Sternapodeme weakly convex, with or without weak, oral projections. Virga small, distinct or pronounced; with or without lateral lamellae. Phallapodeme sometimes heavily sclerotized. Gonocoxite with weakly indicated, rounded, superior volsella; inferior volsella somewhat variably developed, either bilobed or simple, often partly or completely without microtrichia, sometimes with broad spines apically. Gonostylus always with distinct dense microtrichia and setae on inner margin, without crista dorsalis, with normal, weak or without megaseta.

\section{Remarks}

In the key to the males of the Holarctic Orthocladiinae the new species keys without difficulties to couplet 95 - Thalassosmittia (part) thalassophila Bequaert and Goetghebuer (Cranston et al. 1989); in Sæther et al. (2000) it will key to couplet 175, but not further as the eyes are bare and not pubescent; the genus is not included the key to the Central American Chironomidae (Spies et al. 2009).

When including the new species in Thalassosmittia the generic diagnosis has to be emended to include species with bare eyes and reduced palp.
The new species also has a phallapodeme with triangular aedeagal lobe and strongly sclerotized median margin, and a strong, spine-like virga with distinct lateral lamellae. However, it shares with its congeners the characteristically broad, apically rounded anal point, covered with micriotrichia and setae. Further, the gonostylus has brush like setae on the inner margin and the megaseta is weak as in several other species of the genus. The costa is strongly extended, and $\mathrm{R}_{2+3}$ is running and ending closer to $\mathrm{R}_{4+5}$ than to $\mathrm{R}_{1}$.

Wang and Sæther (1993) pointed out that T. montana might deserve a separate genus. The new species might also deserve a new genus, but it appears to differ too strongly from $T$. montana for the two species to be placed in the same genus. For the time being we are therefore probably better served with keeping both in the genus Thalassosmittia.

\section{Thalassosmittia amazonica new species}

(Figs 1-8)

Type material: Holotype male: Brazil, Amazonas State, Manaus, Reserva Adolpho Ducke, Igarapé Barro Branco, 0255'47'S 5958'22”W, 05-08 February 2010, light trap, leg. L.C. Pinho and H.F. Mendes (MZSP).

Etymology: Named after the Amazon region, where the type specimen was collected.

Diagnostic characters: The new species can be easily distinguished from its congeners as it has bare eyes and a reduced palp with only a single palpomere.

\section{Description}

Male $(\mathrm{n}=1)$. Total length $1.41 \mathrm{~mm}$. Wing length $858 \mu \mathrm{m}$. Total length / wing length 1.65. Wing length / length of fore femur 2.76.

Coloration. Head, legs and abdomen light brown; thorax light brown with brown vittae; wings translucent.

Antenna (Fig. 4). With 13 flagellomeres, fully plumed, AR 0.31. Terminal flagellomere $128 \mu \mathrm{m}$ long, antennal groove starts on flagellomere 4 , flagellomeres 2, 3 and terminal with sensilla chaetica.

Head (Fig. 1). Temporal setae 4, consisting of 2 inner verticals and 2 outer verticals. Clypeus with 5 setae. Tentorium, stipes and cibarial pump as in Figure 3. Tentorium $66 \mu \mathrm{m}$ long; $14 \mu \mathrm{m}$ wide. Stipes apparently about $15 \mu \mathrm{m}$ long. Palp (Fig. 2) with 1 palpomere, $29 \mu \mathrm{m}$ long, $18 \mu \mathrm{m}$ wide; with about 8 sensilla clavata, longest $12 \mu \mathrm{m}$ long. 


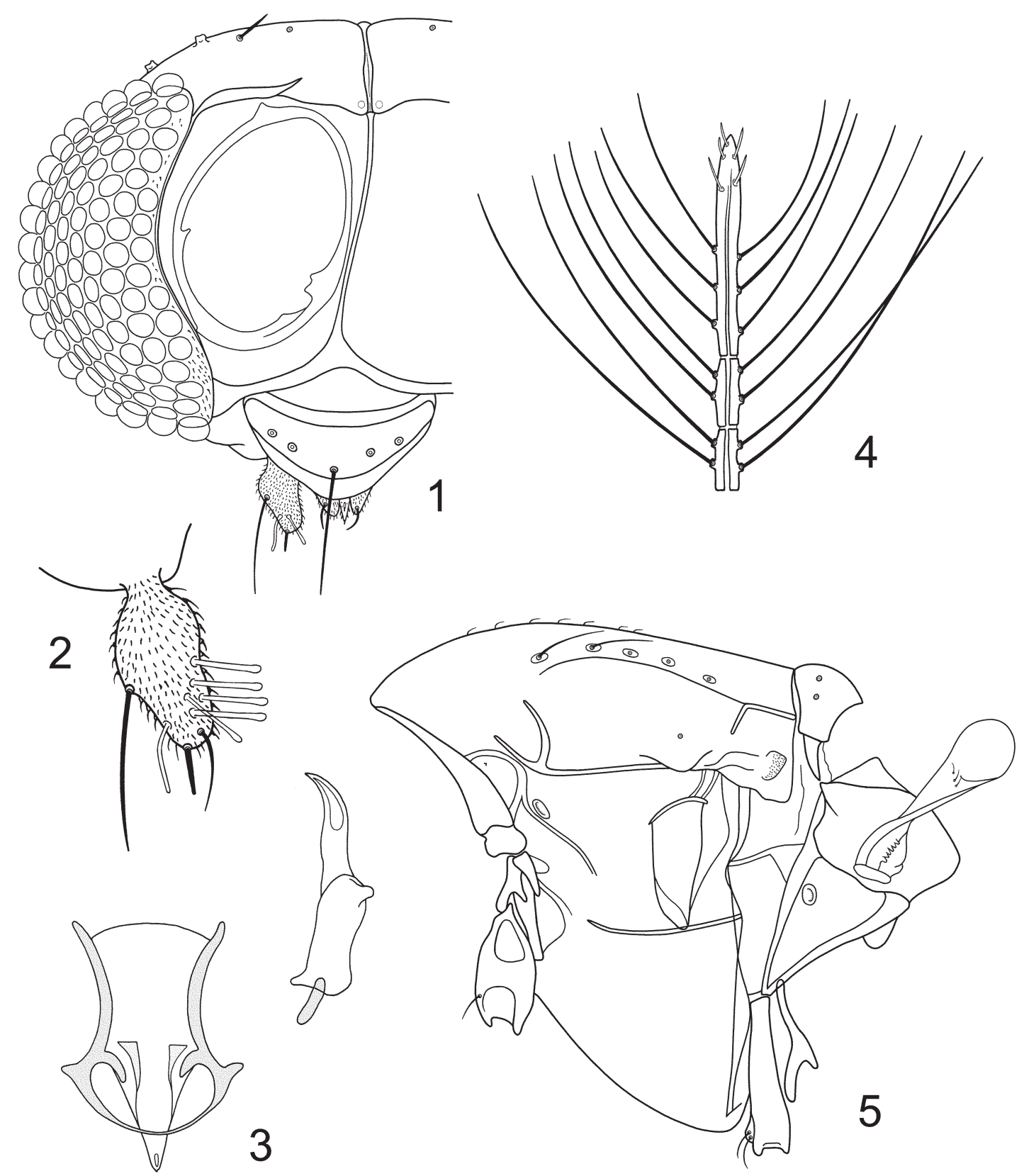

Figures 1-5. Thalassosmittia amazonica $\mathrm{n}$. sp., male. 1, head; 2, palp, ventral view; 3, tentorium, stipes and cibarial pump; 4, apex of antenna; 5, thorax.

Thorax (Fig. 5). Antepronotum without setae. Acrostichals about 7 in mid scutum, dorsocentrals 5; prealar 1. Scutellum with 4 setae.

Wing (Fig. 6). VR 1.41. Wing cuneiform. C extension $105 \mu \mathrm{m}$ long, narrow, without non-marginal setae. Brachiolum with 1 seta, other veins and membrane bare. Squama bare.

Legs. Fore tibia with $29 \mu \mathrm{m}$ long spur; mid tibia lost; hind tibia with $30 \mu \mathrm{m}$ and $11 \mu \mathrm{m}$ long spurs. Width at apex of fore tibia $19 \mu \mathrm{m}$; of hind tibia 22 $\mu \mathrm{m}$. Hind tibial comb reduced, apparently with 5 setae, longest $18 \mu \mathrm{m}$ long, shortest $12 \mu \mathrm{m}$ long.
Sensilla chaetica and pseudospurs absent. Lengths (in $\mu \mathrm{m}$ ) and proportions of legs as in Table 1 .

Abdomen. Tergite I with 3 setae, tergites II-VII with about 8 setae in transverse band, tergite VIII with 10 comparatively short setae in transverse band.

Hypopygium (Figs 7-8). Anal point broadly triangular; $28 \mu \mathrm{m}$ long, $33 \mu \mathrm{m}$ wide at base; with about 9 dorsal and 10 marginal, weak setae. Laterosternite IX with 2 setae. Phallapodeme $70 \mu \mathrm{m}$ long, aedeagal lobe triangular with $55 \mu \mathrm{m}$ long, strongly sclerotized median margin. Transverse sternap- 
Table 1. Lengths (in $\mu \mathrm{m}$ ) and proportions of legs of Thalassosmittia amazonica $\mathrm{n}$. sp., male $(\mathrm{n}=1)$.

\begin{tabular}{llllllllllll}
\hline & $\mathrm{fe}$ & $\mathrm{ti}$ & $\mathrm{ta}_{1}$ & $\mathrm{ta}_{2}$ & $\mathrm{ta}_{3}$ & $\mathrm{ta}_{4}$ & $\mathrm{ta}_{5}$ & $\mathrm{LR}$ & $\mathrm{BV}$ & $\mathrm{SV}$ & $\mathrm{BR}$ \\
\hline $\mathrm{p}_{1}$ & 320 & 388 & 184 & 116 & 76 & 44 & 32 & 0.474 & 3.328 & 3.848 & 3.43 \\
$\mathrm{p}_{2}$ & 352 & - & - & - & - & - & - & - & - & - & - \\
$\mathrm{p}_{3}$ & 356 & 348 & 208 & 118 & 116 & 36 & 28 & 0.598 & 3.060 & 3.385 & 3.75 \\
\hline
\end{tabular}

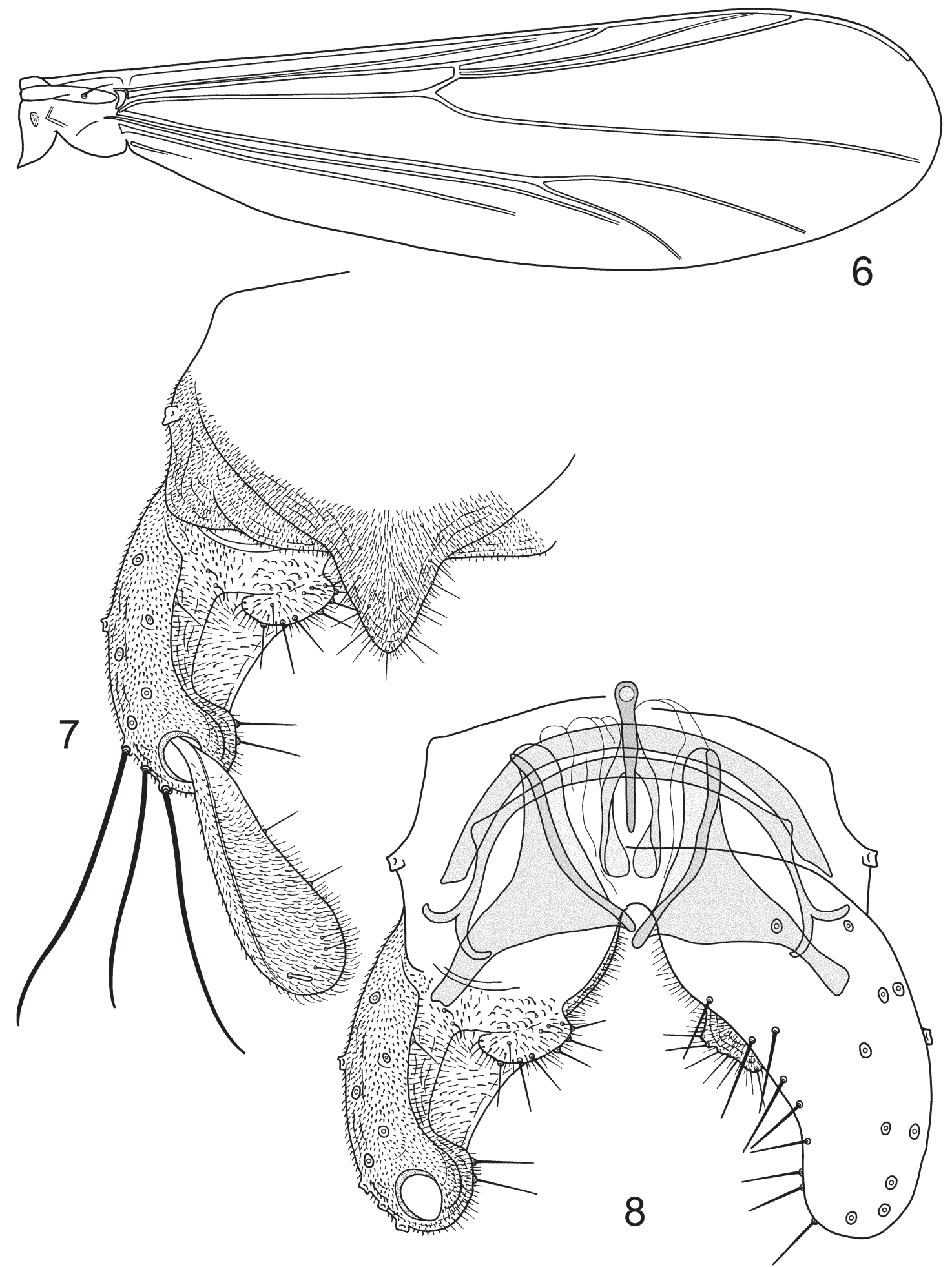

Figures 6-8. Thalassosmittia amazonica n. sp., male. 6, wing; 7, hypopygium, dorsal aspect; 8, hypopygium with anal point and tergite IX removed, dorsal aspect to the left and ventral aspect to the right. 
odeme arched with weak oral projections, $80 \mu \mathrm{m}$ long. Virga consisting of single, strong spine, 44 $\mu \mathrm{m}$ long; with strong, lateral lamellae. Gonocoxite $116 \mu \mathrm{m}$ long. Inferior volsella subrectangular, $14 \mu \mathrm{m}$ long. Gonostylus oar-blade shaped, $79 \mu \mathrm{m}$ long, $23 \mu \mathrm{m}$ wide at its widest point, densely covered with medially directed, long microtrichia and a few weak setae; megaseta weak, $6 \mu \mathrm{m}$ long. HR 1.46. HV 1.78 .

Female and immatures. Unknown.

\section{Distribution and ecology}

The species is only known from the type locality, Reserva Adolpho Ducke, a 10,000 ha reserve in the outskirts of Manaus in the Amazonas State, Brazil. The single male was collected in a light trap situated close to a stream and several temporary pools. The area is covered with primary forest and is relatively flat. During the rainy season numerous small pools are formed scattered on the forest floor.

Reserva Adolpho Ducke is also the type locality for Dicrotendipes fittkaui Epler, Beardius curticaudatus Pinho, Mendes et Andersen, Litocladius neusae Mendes, Andersen et Hagenlund, and Saetherocryptus amazonicus Andersen et Pinho (Andersen and Pinho 2014; Epler 1988; Mendes et al. 2011; Pinho et al. 2013).

\section{Acknowledgements}

Thanks are due to Dr. Neusa Hamada, Instituto Nacional de Pesquisas da Amazônia, Manaus, for setting up the project to increase the knowledge of aquatic insects in the Amazonas State. Gladys Ramirez made the slide preparations. Financial support for field work in Amazonas was provided through a project supported by PRONEX-CNPq (MCT)-FAPEAM [Insetos aquáticos: biodiversidade, ferramentas ambientais e a popularização da ciência para melhoria da qualidade de vida humana no estado do Amazonas] and INPA (MCT).

\section{References}

Andersen, T. and Pinho, L.C. 2014. A new species of Saetherocryptus Andersen et Mendes, 2007 (Diptera: Chironomidae, Orthocladiinae) from the Amazon rainforest, Brazil. - Norwegian Journal of Entomology 61: 160-164.

Andersen, T., Sæther, O.A., Cranston, P.S. and Epler, J.H. 2013. 9. The larvae of Orthocladiinae (Diptera: Chironomidae) of the Holarctic Region - Keys and diagnoses. In: Andersen, T., Cranston, P.S. and Epler, J.H. (Sci. eds): The larvae of Chironomidae (Diptera) of the Holarctic Region - Keys and diagnoses. - Insect Systematics \& Evolution, Supplement 66: 189-386.
Bequaert, M. and Goetghebuer, M. 1914. Deux Chironomides marins capturés sur le littoral belge (Clunio marinus Haliday et Camptocladius thalassophilus nov. spec.). - Annales de la Société Entomologique de Belgique 57: 370-377.

Cranston, P.S., Oliver, D.R. and Sæther, O.A. 1989. The adult males of Orthocladiinae (Diptera: Chironomidae) of the Holarctic region Keys and diagnoses. In: Wiederholm, T. (Ed.) Chironomidae of the Holarctic region - Keys and diagnoses. Part 3 - Adult males. - Entomologica scandinavica, Supplement 34: 165-352.

Epler, J.H. 1988. Biosystematics of the genus Dicrotendipes Kieffer, 1913 (Diptera: Chironomidae) of the world. - Memoirs of the American Entomological Society 36: 1-214.

Mendes, H.F., Andersen, T. and Hagenlund, L.K. 2011. New species and records of Antillocladius Sæther and Litocladius Mendes, Andersen et Sæther from Brazil and Costa Rica (Chironomidae: Orthocladiinae). - Zootaxa 2915: $39-51$.

Morley, R.L. and Ring, R.A. 1972. The intertidal Chironomidae (Diptera) of British Columbia. II. Life history and population dynamics. $-\mathrm{Ca}$ nadian Entomologist 104: 1093-1098.

Pinho, L.C., Mendes, H.F. and Andersen, T. 2013. Revision of Beardius Reiss et Sublette, 1985 (Diptera: Chironomidae), with the description of twenty new species. - Zootaxa 3742: 1-78.

Sæther, O.A. 1969. Some Nearctic Podonominae, Diamesinae and Orthocladiinae (Diptera: Chironomidae). - Bulletin of the Fisheries Research Board of Canada 107: 1-154.

Sæther, O.A. 1977. Female genitalia in Chironomidae and other Nematocera: morphology, phylogenies, keys. - Bulletin of the Fisheries Research Board of Canada 197: 1-211.

Sæther, O.A. 1980. Glossary of Chironomid morphology terminology (Diptera: Chironomidae). - Entomologica scandinavica, Supplement 14: $1-51$.

Sæther, O.A. and Andersen, T. 2011. Chironomidae from Gough, Nightingale and Tristan da Cunha islands. - Zootaxa 2915: 1-19.

Sæther, O.A., Ashe, P. and Murray, D.A. 2000. A.6. Family Chironomidae. In: Papp, L. and Darvas, B. (Eds.), Contributions to a Manual of Palaearctic Diptera (with special reference to flies of economic importance). Appendix. Science Herald, Budapest, pp. 113-334. 
Sasa, M. and Suzuki, H. 1999a. Studies on the chironomid midges of Tsushima and Iki Islands, western Japan: Part 2. Species of Orthocladiinae and Tanypodinae collected on Tsushima. - Tropical Medicine 41(2): 75-132.

Sasa, M. and Suzuki, H. 1999b. Studies on the chironomid midges of Tsushima and Iki Islands, western Japan: Part 3. The chironomid species collected on Iki Island. - Tropical Medicine 41(3): 143-179.

Saunders, L.G. 1928. Some marine insects of the Pacific coast of Canada. - Annals of the Entomological Society of America 21(4): 521-545.

Spies, M., Andersen, T., Epler, J.H. and Watson, C.N. Jr. 2009. Chironomidae (Non-biting Midges). In: Brown, B.V., Borkent, A., Cumming, J.M., Wood, D.M., Woodley, N.E. and Zumbado, M.A. (Eds). Manual of Central American Diptera: Volume 1. NRC Research Press, Ottawa, Ontario, Canada, pp. 437-480.

Storå, R. 1936. Fam. Chironomidae. In Frey, R. (Ed.). Die Dipterenfauna der Kanarischen Inseln und ihre Probleme. Commentationes Biologicae 6(1): 21-30.
Strenzke, K. and Remmert, H. 1957. Terrestrische Chironomiden. XVII. Thalassosmittia thalassophila (Bequ. u. Goetgh.). - Kieler Meeresforschungen 13(2): 263-273.

Sublette, J.E. 1967. Type specimens of Chironomidae (Diptera) in the Canadian National Collections, Ottawa. - Journal of the Kansas Entomological Society 40(3): 290-331.

Tokunaga, M. 1936. Chironomidae from Japan (Diptera), VIII. Marine or seashore Spanioto$m a$, with descriptions of the immature forms of Spaniotoma nemalione sp. nov. and Tanytarsus boodleae Tokunaga. - Philippine Journal of Science 60(3): 303-321.

Wang, X. and Sæther, O. A. 1993. A new species of the 'marine' genus Thalassosmittia Strenzke \& Remmert from Xizang (Tibet), China (Diptera: Chironomidae). - Entomologica scandinavica 24(2): 211-214.

Yamamoto, M. 2004. A catalog of Japanese Orthocladiinae (Diptera: Chironomidae). - Makunagi 21: 1-121. 